\title{
IMPACT OF STUDENT EMOTIONS AND ATTITUDES IN L2 SPANISH BEGINNER STUDENTS IN CHATTANOOGA STATE COMMUNITY COLLEGE (PRELIMINARY RESULTS)
}

\author{
EL IMPACTO DE LAS EMOCIONES Y ACTITUDES DE LOS ESTUDIANTES \\ PRINCIPIANTES DE ESPAÑOL COMO L2 EN EL CHATTANOOGA STATE \\ COMMUNITY COLLEGE (RESULTADOS PRELIMINARES)
}

\author{
Juan Antonio Alonso Santillana \\ Alumno EIDUNED-UNED \\ Chattanooga State Community College \\ jalonso949@alumno.uned.es \\ juan.alonso@chattanoogastate.edu
}

Fecha de recepción: 04-06-2019

Fecha de aceptación: 22-12-2019

\begin{abstract}
This article discusses preliminary results in a doctoral investigation aimed at measuring the impact of beginner student emotions and attitudes on their journey through the Spanish as a second language program at Chattanooga State Community College. One of the working hypotheses is that having a negative attitude about the Spanish language and its speakers in the United States impacts students' decisions to enroll in the program. Once enrolled, anxiety and enjoyment will correlate (the first negatively, the second positively) with student retention and success. However, the institution can intervene positively in enrollment through global and cultural awareness instruction. In turn, Spanish as a second language faculty can have a positive impact in student private and public enjoyment in the Spanish classroom by utilizing emotional intelligence and engaging classroom strategies, thereby increasing student retention and success.
\end{abstract}

KEY WorDS: emotion; motivation; foreign language learning; Spanish; attitudes 


\section{RESUMEN}

Este artículo discute los resultados preliminares de una investigación de tesis doctoral que se propone medir el impacto que las emociones y actitudes de los estudiantes principiantes tienen en su desempeño en el programa de español como segunda lengua en Chattanooga State Community College. Una de las hipótesis de trabajo es que tener una opinión negativa sobre el español y sus hablantes en Estados Unidos tiene un impacto en la decisión de un estudiante de matricularse en el programa. Una vez matriculados, existirá una correlación entre la ansiedad y el disfrute que los estudiantes experimentan en la clase y su perseverancia y éxito. Sin embargo, el centro educativo puede intervenir positivamente en las matriculaciones por medio de instrucción en conciencia global y cultural. A su vez, el profesorado de español como segunda lengua puede incrementar el disfrute público y privado que los estudiantes experimentan en la clase, mediante la aplicación de estrategias educativas atractivas e inteligencia emocional, lo que tendría un impacto positivo en la perseverancia y éxito de los alumnos.

Palabras Clave: emoción; motivación; aprendizaje de lenguas extranjeras; lengua española; actitudes

\section{Introduction}

The intended outcome of this research is to contribute to a better understanding of enrollment, success, and retention on the part of Chattanooga State's students of Spanish, by collecting and analyzing quantitative and qualitative data about the students' emotions and attitudes that influence them and examining how instructor and instruction intervention might impact them. Based on the existing literature, which will be analyzed in the next section, we identify two emotions as determinant in the process studied: a positive emotion, enjoyment, and a negative one, anxiety (ANX).

The confrontation of foreign language (FL) classroom enjoyment vs FL ANX as two key learner-internal variables in the second language (L2) field goes back to Dewaele \& MacIntyre (2014). They construct classroom enjoyment as the combination of creativity, pride, interest and fun experienced by the student in the classroom (private enjoyment, $\mathrm{PE}$ ), and a positive relationship with teachers and peers (social enjoyment, SE). FL ANX is defined as "the worry and negative emotional reaction aroused when learning or using a second language" (MacIntyre, 1999). The present study is the first to attempt to measure these two variables and their interaction with retention and success among American community college students studying Spanish.

The association between a linguistic variety prestige and the social perception of its speakers has been long studied, which led several researchers to explore the correlation between students' attitudes towards the culture associated with a target language the success those students achieved (Gardner \& Lambert, 1972: Acheson et al. 2015). This is the first study focused on the impact of attitudes on students for whom enrolling in an L2 class is often optional, so the focus will expand not just from the connection between 
attitudes and success, but also on how it interacts with the decisions to enroll in the program and, once enrolled, persevere.

The analysis of the collected data expects to find correlations between the abovedescribed internal variables and students' enrollment, retention and success, but also on the degree to which instructors and instruction can influence those internal variables. In turn, that information can be used to develop instructor training that places emphasis on skills that are not traditionally linked to teaching performance in higher education. These skills include emotional intelligence, emotional self-evaluation on the part of the teacher, and the ability to foster a positive learning environment and a positive relationship with students. Also, by shedding light on the impact that student attitudes towards Spanish and its speakers has on enrollment decisions, and on how global and cultural awareness instruction can impact those attitudes, this study could contribute to influence the institutional approach towards promoting global and cultural awareness in and outside the classroom, as it could directly benefit retention rates in second language programs and correct the drop in enrollment these have experienced nationwide in the 2013-2016 period (Looney \& Lusin, 2018).

\section{Background}

\subsection{Enrollment and retention}

Despite the attention community college administrators put on enrollment and retention figures, there is a significant lack of empirical research on retention in language courses in American community colleges (Wesely, 2010). As per enrollment in these courses, the Modern Languages Association periodically publishes a study of their trends, but they just present the figures, without digging into the underlying causes impacting these trends. The last published report, from February 2018 (Looney \& Lusin, 2018), examines the trends between the fall semesters of 2013 and 2016. This study shows a drop in enrollment of $9.2 \%$ across all languages and institutions. This drop is even more acute in two-year institutions, reaching a 15.9\% decrease since 2013 (a staggering 28.6\% since 2009). When we focus on Spanish as an FL, enrollments in this language had an overall drop of $9.8 \%$, but it still accounts for $50.2 \%$ of the total enrollments in L2 programs in higher education (Looney \& Lusin, 2018).

Despite a dearth of research attempting to explain enrollment trends in both four- and two-year institutions of higher education in the United States (US) (Juszkiewizc, 2017 or Ma \& Baum 2016, to name two recent general studies), there is currently no empirical research attempting to explain the specific trends affecting language programs. This study does not intend to fully explain enrollment trends but instead examines the different attitudes towards Spanish and its speakers between students who have decided to enroll and those who declare no intention to do so. 


\subsection{Motivation in $\mathbf{L} 2$ classes}

Motivation in L2 classes has, on the other hand, been extensively researched, with Gardner (1985) being one of the most influential early researchers. A synthesis of motivation research can be found in Boo, Dörnyey, \& Ryan (2015). Dörnyei himself established an L2 Motivational Self System (2005) which is the current framework used to analyze motivation in L2 students, conceptualizing motivation in two self-guides: the ideal L2 self, which represents the ideal L2 speaker the learners want to become, and the ought-to L2 self, which represents the outcome the learners feel they must meet to match third party expectations (friends, family, society at large) and avoid negative outcomes.

\subsection{Attitudes towards foreign languages and their speakers}

It was also within the context of student motivation studies that the attitude towards FLs and their speakers started to arise as a factor in studies performed in the US. Positive social perceptions regarding the study of languages other than English was reported in Rivers et al. (2013), however, the persistence of factors such as cultural isolation and ethnocentrism (Acheson, 2004), language-based discrimination (Lippo-Green, 2012), and the emotionally charged impact of Latino immigration in the US (Fishman, 2004; Acheson et al. 2015; Abrajano \& Hajnal, 2017) contribute to developing a negative perception towards Latinos and the Spanish language in the US.

The impact of the perception of the target language and its speakers in the motivation of L2 learners was studied first by Gardner and Lambert (1972), who focused on the impact that the perception of the French language and Canadian French speakers had on Canadian English speakers learning French. Gardner, Smythe, \& Clément (1978) later developed an Attitudes and Motivation Test Battery (AMTB) designed to measure that perception. Acheson, Nelson, and Luna (2015) adapted this questionnaire to measure the attitudes of high school students in public schools of the state of Georgia towards European Spanish and its speakers, and non-European Spanish speakers and their Spanish, among other elements.

In the last two decades, the link between attitudes and motivation has been studied from many perspectives, including race, home language, gender, globalization, etc. Most studies indicate a connection between positive attitudes and motivation, and there is one study (Cochran et al., 2010) that suggests a correlation between increasing positive attitudes towards the target language and its speakers and achievement gains. A recent study by De Smet et al. (2018) indicates that target language perception appears to play a major role in student emotions in immersion courses, with French-speaking Belgian students performing better in English immersion classes than in Dutch immersion classes due to this factor. 


\subsection{Positive and negative emotions in the $L 2$ classroom}

The role of learners' positive and negative emotions in the L2 classroom has become a source of interest for researchers more recently. It was within motivation research than L2 learners' emotional states began to be included, first in Dörney \& Ushioda (2009), and later in MacIntyre \& Gtegersen (2012) and Papi \& Teimouri (2014). Most of the discussions in these lines of research have focused on a negative emotion —classroom ANX - which had been identified much earlier as an influencing factor in the L2 class (Horwitz, Horwitz, \& Cope, 1986; MacIntyre \& Gardner, 1989). They first developed an FL classroom ANX scale (FLCA). The current consensus is that episodes of anxiety can be triggered by a specific event in the class, but it is also linked to the experiences students have accumulated over time in their interactions with the target language. This consensus also attributes to anxiety having a debilitating effect in the learner (reviews in Horwitz, 2017 and MacIntyre, 2017).

The study of the impact of positive emotions within the context of language learning is more recent, with Dewaele \&McIntyre (2014) and MacInture \& Gregersen (2014) setting off this line of research, developing a Foreign Language Enjoyment scale (FLE). These authors focus on a set of positive emotions, labelled enjoyment, which according to their research helps learners achieve better results in a target language. Recent studies have linked enjoyment to the ideal-self aspect of motivation, connected to the satisfaction a learner experiences when an internalized goal is achieved (Dewaele \& Dewaele, 2017, and Saito et al., 2018). In Saito et al., enjoyment is divided into PE, which is experienced by the individual because of its interaction with the target language, and SE, which is a collective feeling experienced because of social interaction with peers and instructor in the classroom. Enjoyment and anxiety seem to show a moderate negative correlation, which highlights the fact that they are partially connected, but essentially two different emotional dimensions (Dewaele et al., 2017). These authors highlight the importance of studying both emotions simultaneously to better understand their impact on learners.

The potential impact of instruction on student attitudes and emotions has been frequently discussed in many of the studies dealing with attitudes towards Spanish in the US (both by English speakers and Spanish heritage speakers, in Acheson et al., 2015, or Leeman, 2015), and with the impact of negative and positive emotions in the classroom (Saito et al., 2018). These studies indicate positive results in learners' attitudes towards Spanish as a result of introducing global and cultural awareness activities designed to promote cultural empathy, and positive results in enjoyment by introducing meaningful, unpredictable, motivation-enhancing activities into their lessons. No study to date has found relevant evidence of both instruction and instructor having an impact on classroom ANX. 


\section{Research questions and hypotheses}

The research questions of this study are:

- To what extent do students' linguistic and cultural attitudes impact enrollment in a Spanish L2 classroom at Chattanooga State Community College?

- To what extent do student ANX, PE and SE in the classroom correlate with retention and success in that same population?

- To what extent do instructors and instruction have an impact on those emotions?

From these questions, the elicited working hypotheses are:

I. Having a negative attitude about the Spanish language and its speakers in the United States has a negative impact on motivation and enrollment.

II. After enrollment, classroom ANX and the enjoyment students feel in the second language acquisition (SLA) classrooms will correlate (the first negatively, the second positively) with student retention and success.

III. Instruction will have an impact on PE, whereas a positive relationship between faculty and students will have an impact on public enjoyment. Both will be positively correlated with retention, and success.

\section{Methods}

\subsection{The sample: Chattanooga State Community College students}

Chattanooga State is one of thirteen community colleges administered by the Tennessee Board of Regents system. In the fall of 2018, Chattanooga State had 8,241 students enrolled, roughly half of them full-time (4072), and employed 241 full time and 321 part time faculty. The foreign language section is modest, with two full-time instructors and four part-time ones. There were 161 students enrolled in Spanish classes at the beginning of the fall 2018 semester, 39 in French, and 22 in German, for a grand total of 222 students enrolled in L2 programs, or $2.6 \%$ of total enrollment. Some of these students were enrolled in online classes, and some on campus. This study focuses on the 72 students who were enrolled in the first semester of Spanish at the beginning of the fall of 2018. Of these, two refused to participate in the study, and 70 took the first survey, administered during the second week of classes. Fifty-eight of them took the second survey, administered during the sixth week, so 12 students (16.6\%) had dropped out of the first semester of Spanish L2 (SPAN1010) over the first six weeks of classes. Chattanooga State's retention rate over the period of a year is $52.6 \%$, so retention amongst these 70 students is being measured over a year to see how the rate compares. 


\subsection{Subject categories}

Chattanooga State enrolls three types of students:

- Dual enrollment students: These are high school students who take community college classes in order to receive both high school and college credit for any given passed course. It is a quite popular hybrid program and, as a result, $14.9 \%$ of Chattanooga State students are 17 or younger. The most important characteristic of this group in regard of this study is that their enrollment and retention decisions are often made by their parents and/or advisers. Also, an L2 sequence is required for their graduation, so they have fewer opportunities to challenge their educational options. Many of them have had previous exposure to FLs. This explains the overrepresentation of this group of students in Spanish classes, with 19 (27\%) of the students participating in this study belonging to this group.

- Traditional students: These are college students between the ages of 18 and 24 . Decisions are usually made on their own, with some influence from parents and advisers. FL study is required in a limited number of majors, and students are offered the opportunity to change theirs to a very flexible "general transfer degree" that excludes FL from the requirements. Many of these students have had previous exposure to FLs. $55.9 \%$ of Chattanooga State enrollment belongs to this group. As do $42(60 \%)$ of the students in this study.

- Non-traditional students ( 25 and older): There has been a surge of these students in Tennessee community colleges this year, due to the impact of the Tennessee Reconnect initiative, which offers free tuition to qualifying applicants. Students in this group usually make their own education decisions, with some influence from their advisers. Many of them did not have any previous exposure to FLs. $29.1 \%$ of Chattanooga State students are 25 and older, and they are underrepresented in Spanish classes: only 9 (13\%) participants in this study belong to this group.

\subsection{Enrollment, retention, and success rate among Spanish students.}

The chart below shows the trends in enrollment and semester-to-semester retention in Chattanooga State's beginner Spanish courses. The data reflects results consistent with the Modern Language Association of America (MLA) study for the entire country (Looney \& Lusin, 2018), with a very significant drop in 2016. The partial recovery in 2018 moderates the effect of that drop, which leaves the 2014-2019 enrollment trend at $-19.85 \%$. The total enrollment at Chattanooga State fell by $13.2 \%$. As per retention, the rates of fall to spring retention in FLs go from $42.7 \%$ in 2015-2016 to 56\% in 2016-2017. There is a significant anomaly in 2017-2018 (just 33\% of students returned to take the second semester of Spanish, SPAN1020) which falls beyond the scope of the current study. Chattanooga State does not measure retention of its general population from semester to semester, but the fall to fall retention in the period of 2014-2017 hovered between 52 and 54.50\%. 


\section{TABLE I}

Enrollment and retention trends in Chattanooga State's Spanish L2 program

\begin{tabular}{|l|c|c|}
\hline Academic Year & $\begin{array}{c}\text { Fall 2018 SPAN1010 } \\
\text { (Year-to-year enrollment trend) }\end{array}$ & $\begin{array}{c}\text { Spring 2019 SPAN1020 } \\
\text { (Fall-spring retention) }\end{array}$ \\
\hline $2014-2015$ & 131 & $62(47.3 \%)$ \\
\hline $2015-2016$ & $145(+10.6 \%)$ & $62(42.7 \%)$ \\
\hline $2016-2017$ & $100(-31 \%)$ & $56(56 \%)$ \\
\hline $2017-2018$ & $93(-7 \%)$ & $31(33 \%)$ \\
\hline $2018-2019$ & $105(+12.9 \%)$ & $58(55.2 \%)$ \\
\hline
\end{tabular}

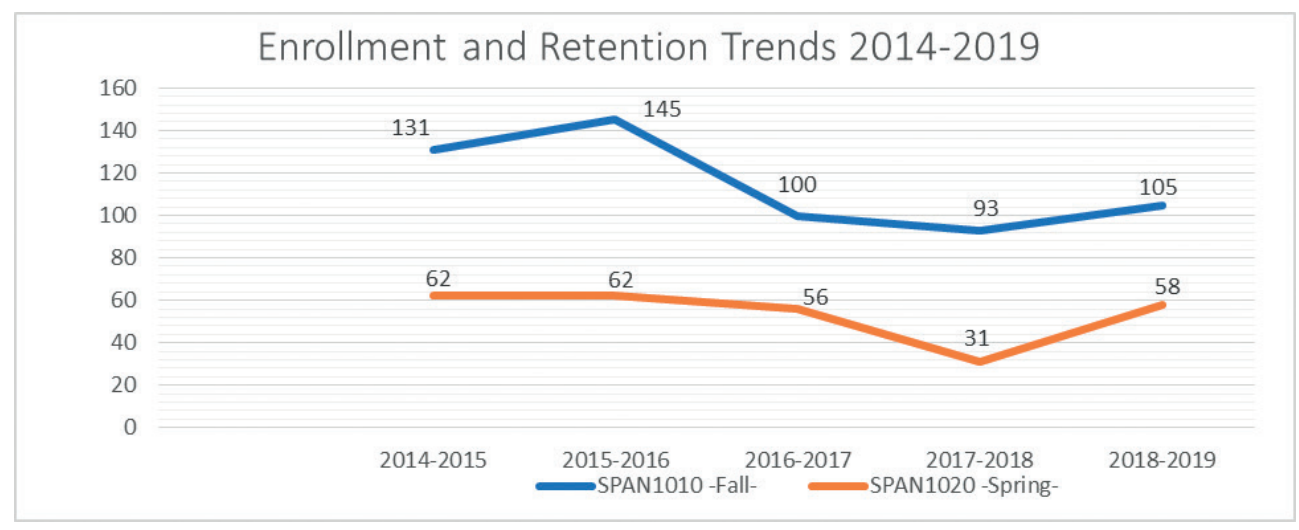

FIGURE I

Enrollment and retention trends in Chattanooga State's Spanish L2 program

\subsection{The experiment}

This experiment is part of a mixed methods design, including a quantitative longitudinal study of how 70 community college students of Spanish fare in their journey through the Spanish program at Chattanooga State Community College from the fall of 2018 through the end of the spring semester of 2019. Retention and success are measured from semester to semester, the latter understood in terms of academic results and the enhancement of performance in Spanish as an L2. These measurements will be compared with students' attitudes towards the Spanish language and Spanish speakers, their general emotional well-being, and the emotions experienced in the L2 classroom, focusing on both negative emotions, such as ANX, and positive emotions, such as enjoyment. In order to make the collected data regarding attitudes towards the Spanish language and its speakers relevant, the question battery designed to measure these elements was administered to a 
control group of 61 students who had not enrolled in any Spanish as an L2 classes. These were students from three English Composition 1 (ENGL1010) classes, which is a general requirement for students enrolled in any degree program at Chattanooga State.

The quantitative portion of the study consists of three surveys. The first one was administered during the second week of SPAN1010 classes. The first section of this survey collects demographic data and subjects' previous academic experience with Spanish as an L2, if any. The second section questions subjects about their reasons to enroll in the class, in a battery designed specifically for this study. The third section is an adaptation of Gardner's AMTB test (Gardener et al., 1978) and intends to measure attitudes towards the Spanish language and its speakers in the US. The fourth and final section aims to measure ideal-self and ought-to-self motivation, following Dörnyei's L2 Motivational Self System (Dörnyei, 2009).

The second survey was administered to the same cohort in the sixth week of classes, and it was divided in three sections. The first section measures students' self-perception of their academic progress up to that point; the second measures instructor and instruction perception (adapting an instrument designed by Andrea Franco Magdalena for a study exploring affective variables in the classroom that is pending publishing); and the third measures ANX, PE and SE, adapting Dewaele \& MacIntyre's FLE and FLCA scale as used by Saito et al. (2018).

The third survey was administered in the last week of classes, and measured the same elements as the second survey, as well as the students' intentions regarding enrollment in SPAN1020. It also had an added question to measure an aspect of the impact of studentteacher relationship on ought-to-self motivation.

This quantitative study will be followed by a qualitative one aimed at exploring further the contextual factors that influence the emotions described above, and the potential avenues to impact them positively. The data used to draw the preliminary conclusions in this paper was taken from the first two quantitative surveys.

The surveys were administered during class time at a computer classroom at Chattanooga State, using Google Forms. All students signed a release form provided by the institution, which authorized the research. The legal tutor of each minor student who participated in the experiment signed the release form prior to the student being allowed to participate. Incomplete responses (two) were eliminated from the first survey.

\section{RESULTS}

\subsection{First Survey}

Reasons to enroll in a SPAN1010 class

Source, this study. 
Items used to measure students' reasons to enroll in a Spanish 1010 class:

1. I am taking Spanish in college only because it is a requirement for my degree.

2. If I could take any elective in the catalog to fulfill this requirement, I would still take Spanish.

3. English-speaking Americans should be able to opt out of FL classes in college if they don't interest them.

4. I am not taking any more Spanish classes in college once I am done with my requirement.

Scores interpretation: Strictly to fulfill a requirement: 1 // Strictly for personal or professional reasons, beyond the requirement: 5

The results for the SPAN1010 cohort group, the Average (AV), Median (MED), and Standard Deviation (SD) were 3.5, 3.5, and 0.90 respectively. These results indicate that students at Chattanooga State are moderately motivated to enroll in Spanish for personal and professional reasons, beyond the requirement. However, the SD indicates a wide variety of answers.

The AV for honors students was 3.76. AVs by age were $\mathbf{3 . 3}$ for students 17 or under, 3.56 for students $18-24$ and $\mathbf{3 . 6 2 5}$ for students 25 or above. The AVs by gender were $\mathbf{3 . 2 7}$ for males and $\mathbf{3 . 6 3}$ for females. As we stated before, students 17 or under are less free to make decisions than the rest and are also subject to a more rigid L2 requirement by the State. As a result, they are less likely to enroll for personal or professional reasons than the rest of subjects. The same score differential exists between males and females.

Attitudes towards the Spanish language and Spanish speakers in the US:

Source: An adaptation of the Attitudes and Motivation Test Battery (AMTB) by Garner et al. (1978) to study the affections of learners of French in Canada, as applied by Acheson et al. (2015) for learners of Spanish in the state of Georgia.

Items used to measure attitude towards Spanish language:

1. Because the US is relatively far from many countries speaking other languages, it is not important for Americans to learn Spanish.

2. English-speaking Americans should make a greater effort to learn the Spanish language.

3. The increasing presence of the Spanish language around us is a threat to American culture.

4. The more I learn about Hispanic Americans, the more I want to be fluent in their language.

5. I enjoy listening to people who speak Spanish.

Scores interpretation: Very negative attitude: 1 // Very positive attitude: 5 
The results for the SPAN1010 cohort group were AV 4.15, MED 4.2, and SD 0.56. This indicates most students enrolled in Spanish 1010 have a positive attitude towards the Spanish language.

The AV for honors students was $\mathbf{4 . 4 4}$. AVs by age were $\mathbf{3 . 3}$ for students 17 or under, 4.19 for students $18-24$, and $\mathbf{4 . 4}$ for students 25 or above. The AVs by gender were $\mathbf{3 . 9 1}$ for males and 4.3 for females. The results for the control group were AV 3.49, MED 3.5, and SD 0.49. These results confirm the fact that students 17 or under have less freedom to enroll than students 18 or older. In fact, not only did they score significantly lower than the rest, their scores are also in line with those achieved by the control group. Once again, we detect a clear difference by gender, but not as wide as in the previous indicator.

Items used to measure attitude towards Spanish speakers:

1. For the most part, Hispanic-Americans are sincere and honest.

2. As a general rule, Hispanic-American residents bring drugs and gangs with them.

3. Most Hispanic-Americans are very hardworking.

4. Hispanic-Americans are a burden on this country's economy.

5. Hispanic-American immigrants should assimilate or go back to their countries.

6. I would like to know more Hispanic Americans.

7. Hispanic-American immigration is making this country a worse place to live.

8. Some of our best citizens are of Hispanic-American descent.

9. A significant percentage of Hispanic-Americans are here illegally.

10. The Hispanic-American heritage is a very important part of our U.S. American identity.

Scores interpretation: Very negative attitude: 1 // Very positive attitude: 5

The results for the SPAN1010 cohort group were AV 4.13, MED 4.2, and SD 0.45. These results align closely with those measuring attitude towards the Spanish language. Most subjects have a clearly positive attitude towards both the language and their speakers.

The AV for honors students was 4.2. AVs by age were $\mathbf{4 . 0 1}$ for students 17 or under, 4.12 for students $18-24$, and $\mathbf{4 . 2 3}$ for students 25 or above. The AVs by gender were $\mathbf{3 . 9 2}$ for males and $\mathbf{4 . 2 6}$ for females. The results for the control group were AV 3.43, MED 3.55, and SD 0.70. The differences by gender and age group are more moderate for this indicator. In this case, students 17 or under do not align with the control group and clearly show a more positive attitude towards Spanish speakers. Having a native Spanish speaker instructor could explain these results. Further research may confirm or reject this. 


\subsection{Second and Third Surveys}

\section{The instructor/instructional factor}

In order to obtain information from the subjects regarding their perception of their instructor and the instruction they receive, the following items adapted from Andrea Franco Magdalena (pending publishing) were included in the survey.

Items used to measure students' perception of instructor and instruction:

1. What is your attitude towards your current Spanish instructor?

2. How strict is your instructor?

3. How friendly/approachable is your instructor?

4. Your instructor cares about you

5. Your instructor is helpful

6. How frequently does your instructor use Spanish in class?

7. Is his/her typical Spanish class session predictable? (You always do similar activities, in similar order)

8. His/her classroom assignments keep you engaged and actively participating.

9. The activities you do in class help you improve your Spanish

Items 1-5 measure the relationships between the student and the instructor, whereas 6 through 9 measure the perception of the instructional activities used in class.

Below are the results obtained for the first five items. A score of $\mathbf{1}$ implies a very poor relationship with the instructor, whereas a score of $\mathbf{5}$ implies a very good relationship with $\operatorname{him} /$ her.

The results for the SPAN1010 cohort group were AV 4.4, MED 4.4, and SD 0.45. Most subjects appear to have a very positive perception of their instructor.

The AV for honors students was $\mathbf{4 . 5 5}$. AVs by age were $\mathbf{4 . 2 4}$ for students 17 or under, 4.53 for students $18-24$, and $\mathbf{4 . 2 8}$ for students 25 or above. The AVs by gender were $\mathbf{4 . 4 3}$ for males and $\mathbf{4 . 3 7}$ for females. There are minimal differences based on demographics, with non-traditional students scoring lower than traditional ones (ages 18-24).

As per items 6-9, a score of $\mathbf{1}$ implies a very poor perception of instruction, whereas a score of $\mathbf{5}$ implies a very good one.

The following results were obtained from the SPAN1010 cohort group: AV 3.89, MED 3.75, SD 0.36. Students participating in this study value their L2 instruction moderately. Less than they value their instructor.

The AV for honors students was $\mathbf{3 . 8 5}$. AVs by age were $\mathbf{3 . 8}$ for students 17 or under, 3.92 for students $18-24$, and $\mathbf{3 . 9 5}$ for students 25 or above. The AVs by gender were $\mathbf{3 . 9 7}$ 
for males and $\mathbf{3 . 8 5}$ for females. There are no significant differences in the results obtained for this battery due to age or gender.

Enjoyment (SE and PE) and ANX in the classroom:

Source: An adaptation of the FLE and FLCA items used by Saito et al. (2018).

Items used to measure PE:

1. I don't get bored in Spanish class

2. I enjoy my Spanish class

3. I am a worthy member of the Spanish class

4. In class, I feel proud of my accomplishments

5. It's cool to know Spanish

Scores interpretation: Very low PE: 1 // Very high PE: 5

The results for the SPAN1010 cohort group at week six (second survey) were: AV 3.94, MED 4, SD 0.74. This means subjects declare a high level of PE in their L2 class, but the large SD reveals internal disparity.

The AV for honors students was 4.06. AVs by age were $\mathbf{3 . 6 5}$ for students 17 or under, 4.04 for students 18-24, and $\mathbf{4 . 2}$ for students 25 or above. The AVs by gender were $\mathbf{3 . 7 7}$ for males and $\mathbf{4 . 0 3}$ for females. These results mirror those obtained to measure reasons for enrolment and attitude towards the Spanish language: male subjects, and those 17 or under (with less freedom to choose to enroll in an L2 class) score lower than the rest of respondents.

The results obtained from the remaining subjects at completion (third survey) were: AV 4.11, MED 4.2, SD 0.65. The moderate increase in the results may be because students dropping out early did not participate in the last survey.

Items used to measure SE:

1. My Spanish class is a positive environment

2. It's fun to learn Spanish

3. My classmates are nice

4. There is a good atmosphere in my class

5. We laugh a lot in my class

Scores interpretation: Very low SE: 1 // Very high SE: 5 
The results obtained from the SPAN1010 cohort group cohort group at week six (second survey) were: AV 4.12, MED 4, SD 0.49. This means subjects declare a high level of SE in their L2 class. SD is lower for this category, which is consistent with the collective nature of social enjoyment.

The AV for honors students was 4.45. AVs by age were $\mathbf{3 . 8 9}$ for students 17 or under, 4.25 for students $18-24$, and $\mathbf{4 . 2}$ for students 25 or above. The AVs by gender were $\mathbf{3 . 9 1}$ for males and $\mathbf{4 . 2}$ for females. Same as with the previous indicator, male and younger subjects declare less enjoyment than the rest.

The results obtained from the remaining subjects at completion (third survey) were: AV 4.41, MED 4.4, SD 0.44. This can be explained due to the positive effect time may have in social relationships in the classroom. Also, students who dropped out early are not participating in this third survey, driving the enjoyment scores up.

By combining SE and PE, we obtain a total enjoyment score. The SPAN1010 cohort scores at week six (second survey) were AV 4.03, MED 4, and SD 0.57.

The AV for honors students was $\mathbf{4 . 2 5}$, AVs by age were $\mathbf{3 . 7 7}$ for students 17 or under, 4.15 for students $18-24$, and $\mathbf{4 . 2}$ for students 25 or above. The AVs by gender were $\mathbf{3 . 8 2}$ for males and $\mathbf{4 . 1 2}$ for females.

The SPAN1010 cohort scores at completion (third survey) were AV 4.26, MED 4.25, and SD 0.50. These results match the trends observed for PE and SE individually.

Items used to measure classroom ANX:

1. Even if I am well prepared for my Spanish class, I feel anxious about it

2. I always feel that the other students speak Spanish better than I do

3. I can feel my heart pounding when I'm going to be called on in Spanish class

4. I don't worry about making mistakes in Spanish class

5. I feel confident when I speak in Spanish class

6. I get nervous and confused when I am speaking in my Spanish class

7. I start to panic when I have to speak without preparation in Spanish class

8. It embarrasses me to volunteer answers in my Spanish class

Scores interpretation: Very low ANX: 1 // Very high ANX: 5

ANX results for the SPAN1010 cohort group at week six (second survey) were AV 3.14, MED 3.25, and SD 0.78. This means Chattanooga State L2 students participating in this study declare feeling moderate levels of anxiety in the classroom. SD indicates a large disparity within the group.

The AV for honors students was 2.99. AVs by age were $\mathbf{3 . 3 2}$ for students 17 or under, 3.08 for students $18-24$, and $\mathbf{3}$ for students 25 or above. The AVs by gender were $\mathbf{2 . 8 8}$ for males and $\mathbf{3 . 2 8}$ for females. Students 17 or under declare more anxiety than any other 
group, but this time, male students do not match their trend, as they did in the previous indicator. This suggests male subjects may just be underreporting emotions, whereas younger subjects are more likely to enroll in an L2 class against their personal wishes, simply to fulfill a requirement.

The SPAN1010 cohort scores at completion (third survey) were AV 3.21, MED 3.12, and SD 0.83. The unique nature of classroom ANX makes it the only emotion measured in this study that gets worse as the semester progresses, even though that increase is very small (+0.07). SD is also wider at the end of the semester than it was six weeks into it.

\section{DISCUSSION}

\subsection{Attitudes}

Voluntary enrollment in Spanish shows a mild correlation with enjoyment (0.332), particularly SE (0.335). There is a weak negative correlation between enrolling voluntarily and ANX (-0.179). The attitude towards the Spanish language shows a strong correlation with ideal-self motivation (0.522) and enrolling in the class for personal reasons $(\mathbf{0 . 5 7 2})$. There is a small negative correlation between attitude towards the Spanish language, oughtto-self motivation (-0.145) and ANX (-0.145), and a positive one with SE (0.345) and private enjoyment $\mathbf{( 0 . 1 9 4 )}$.

The attitude towards Hispanic Americans shows a milder correlation also with idealself-motivation $(\mathbf{0 . 2 5 5})$ and enrolling in the class for personal reasons $(\mathbf{0 . 2 2 9})$. There is a mild correlation between this attitude and enjoyment in the classroom $\mathbf{0 . 2 1 2}$ for SE, and $\mathbf{0 . 1 2}$ for PE, respectively). There is also a significant correlation between positive attitude and ANX in the class (0.330). This is perhaps due to females being generally more sympathetic (4.26, vs $\mathbf{3 . 9 2}$ for males) and more prone to this type of ANX (3.27, vs $\mathbf{2 . 8 8}$ for males).

When the results of students enrolled in SPAN1010 are compared to the student general population control group, there is a statistically significant difference in the scores, with a P-Value of $\mathbf{- 0 . 0 0 5}$ for attitudes towards the Spanish language and one of $\mathbf{0 . 0 2 3}$ for attitudes towards Spanish speakers. We can appreciate the difference in median scores in the chart below: 


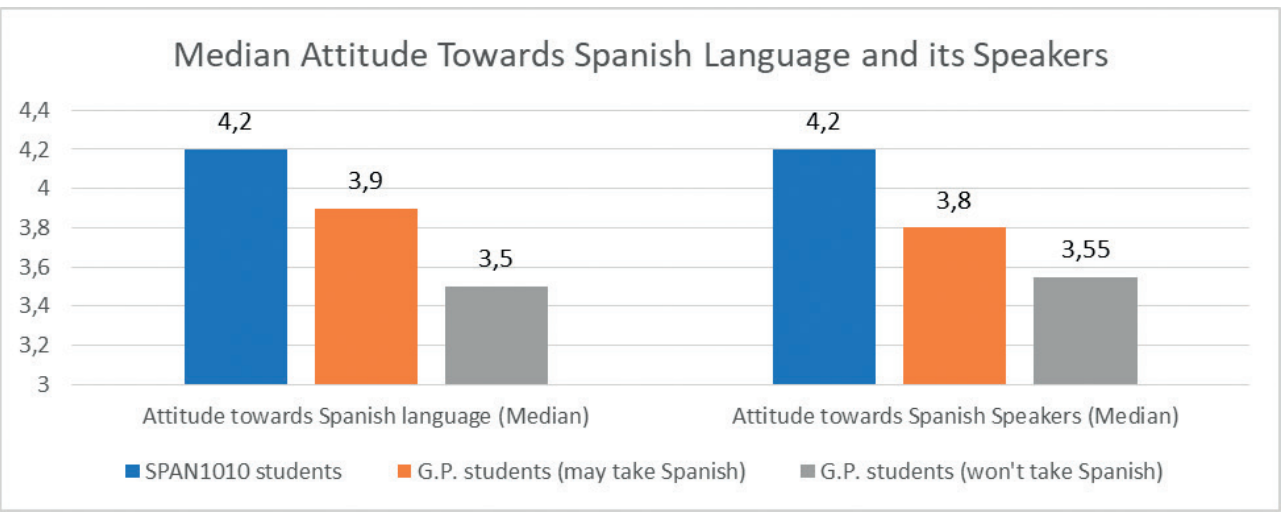

FigURE 3

Median attitude towards Spanish language and its speakers. SPAN1010 students vs control group (may take Spanish) vs control group (will not take Spanish)

As the numbers above indicate, there is a correlation between enrolling in Spanish and having a positive perception of both the language and its speakers. There is also a strong correlation between both attitudes $(\mathbf{0 . 4 4 8}$ among the SPAN1010 cohort, $\mathbf{0 . 7 2 2}$ among the control group students). These findings match those in preexisting literature regarding a correlation between positive social perceptions and studying an L2 (Rivers et al., 2013), and the emotionally charged impact of Latino immigration in the US and its effect on learners (Acheson et al., 2015). Also, it is the first time those attitudes are linked to the intention to enroll in a Spanish L2 class at an American community college. Acheson et al.'s study established that global and cultural awareness instruction can have an impact on learners' attitudes. From these results it could be inferred that a similar type of instruction in general education courses at Chattanooga State could improve these attitudes in the school's general population, and potentially have a positive impact on enrollment in Spanish as an L2.

This factor alone does not explain the significant drop in enrollment in Spanish in American two-year institutions unveiled by the latest MLA report, but it is safe to say that it is an easily available avenue for those institutions to have a positive impact on those figures.

\subsection{Motivation}

Ideal-self motivation is strongly correlated with enrolling in Spanish voluntarily (0.531). There is a mild correlation between this type of motivation and total enjoyment at week six (0.372), which becomes much stronger at completion (0.655), and has virtually no correlation with ANX (-0.025 at week six, -0.069 at completion). These results partially confirm the findings of Saito et al. (2018), which also found a correlation between 
ideal-self motivation and enjoyment; however, the negative correlation between that type of motivation and classroom ANX do not replicate in this group of subjects.

Ought-to-self motivation shows a very weak correlation with emotions, and a curiously negative one with enjoyment (-0.178), affecting SE in particular (-0.256). This negative correlation is maintained at completion (-0.102 for total enjoyment, $\mathbf{- 0 . 1 3 3}$ for SE). There is also a negative correlation between ought-to-self motivation and enrolling in Spanish for personal reasons (-0.182). The correlation between this type of motivation and ANX is also very low at six weeks $(\mathbf{- 0 . 0 5 2})$, but it grows a bit at completion $(\mathbf{0 . 1 8 7})$. These results match the findings of Saito et al. (2018), which failed to find a significant connection between motivation and ANX, and between ought-to-self motivation and any emotions.

\subsection{Positive and negative emotions}

Enjoyment and ANX are negatively correlated with each other, but it is not a strong correlation, matching the results obtained by Dewaele \& Dewaele (2017). The negative correlation between both is $\mathbf{- 0 . 1 4 2}$ at week six (-0.284 at completion). Finally, social and private enjoyment are strongly correlated both at week six (0.705) and at completion (0.698).

Also, as described in previous studies, there is a significant correlation between perception of the effectiveness of instruction and classroom enjoyment $(\mathbf{0 . 5 1 8})$, which particularly impacts private enjoyment $(\mathbf{0 . 5 6 6})$. There is virtually no correlation between instructional perception and classroom ANX. It is interesting to note that the personal relationship with the instructor also has a significant impact on enjoyment $(\mathbf{0 . 4 2 2})$, this time more closely correlated with SE (0.533). As before, there is virtually no correlation between the relationship with the instructor and classroom ANX. These results are very interesting because they indicate that both engaging instructional activities and developing a positive personal relationship with students can contribute to improving learners' enjoyment in a complementary fashion, with the first having a stronger impact on PE, and the second one in SE.

\subsection{Early attrition: characteristics}

Between the first and the second surveys (second week of class and sixth week of class), 12 participants from the original cohort of 70 had already dropped out of their classes $(17.15 \%)$. As predicted initially, only two of them belonged to the 14-17-year-old group (for them, dropping a class now implies having to take it again in the future), whereas the remaining 10 belonged to the other two age groups ( 7 are 18-24, 3 are 25 and above). The most striking differences between this group and the one that persisted are their reasons for enrollment, their attitude towards Spanish speakers, and their ideal-self motivation, as can be seen in the chart below: 


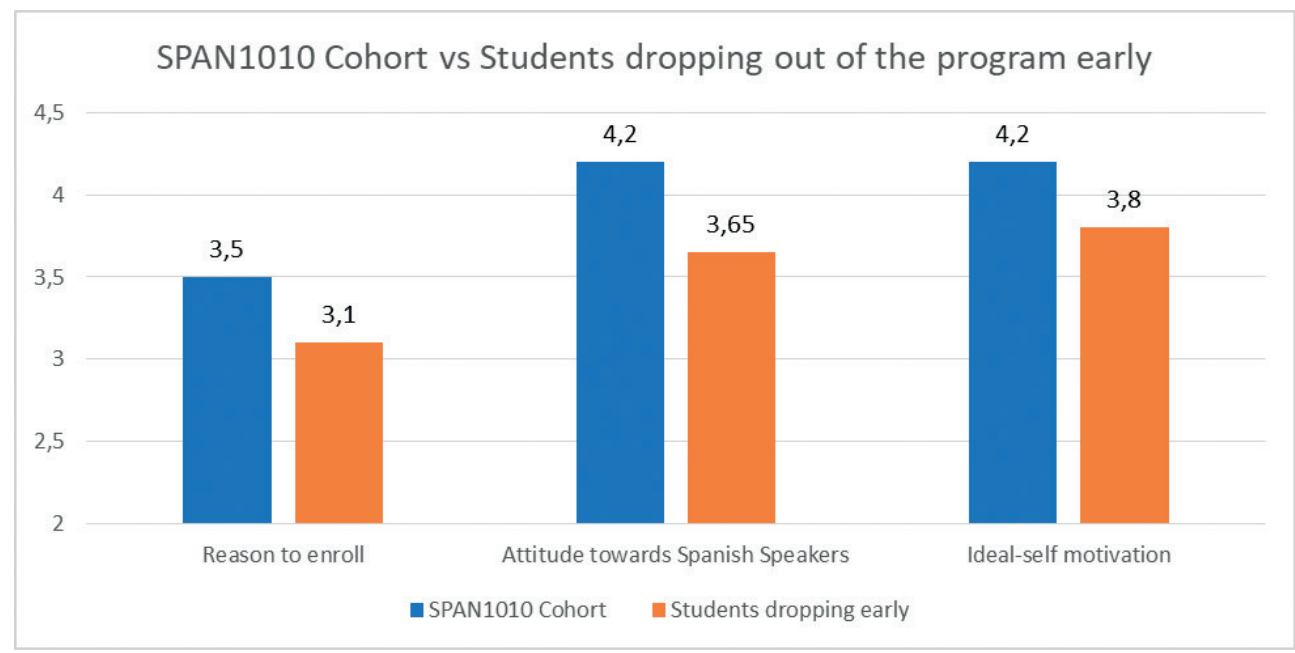

FiguRE 4

Most significant divergence in results obtained from subjects dropping out early and the complete SPAN1010 cohort.

Their results for attitude towards Spanish language and ought-to motivation are very similar to those for the rest of the group. It is important to note than only two respondents in the original survey had an overall negative opinion of Spanish speakers (less than $\mathbf{3}$ ), and both are among those who abandoned the class. These findings also support the hypothesis that students with a lower opinion of Spanish and its speakers are less likely to pursue L2 education. Also, the low score in ought-to-self motivation for the entire cohort under study attests to their perception that most of their peers consider studying Spanish unimportant. It can be concluded that the data collected from students who dropped out early supports the hypothesis that students with a negative opinion of Spanish speakers stay away from Spanish as a FL, and those few that end up enrolling in these classes despite this fact (like the twelve in this sample) are more likely to drop out.

\subsection{Late attrition: characteristics}

Late attrition affected eleven subjects: three who dropped out between week 6 and 15, and nine who finished and passed the course, but chose not to enroll in SPAN1020 the next semester. Those who chose not to return despite successfully completing the course present very similar characteristics, as seven of them belonged to the 14-17 age group. They also scored significantly lower than those who remained in the program in private enjoyment (3.8 vs 4.2), and both ideal-self (3.35 vs 4.12) and ought-to-self (2 vs 2.44$)$ motivation, and higher in classroom ANX (3.4 vs 3.1). 


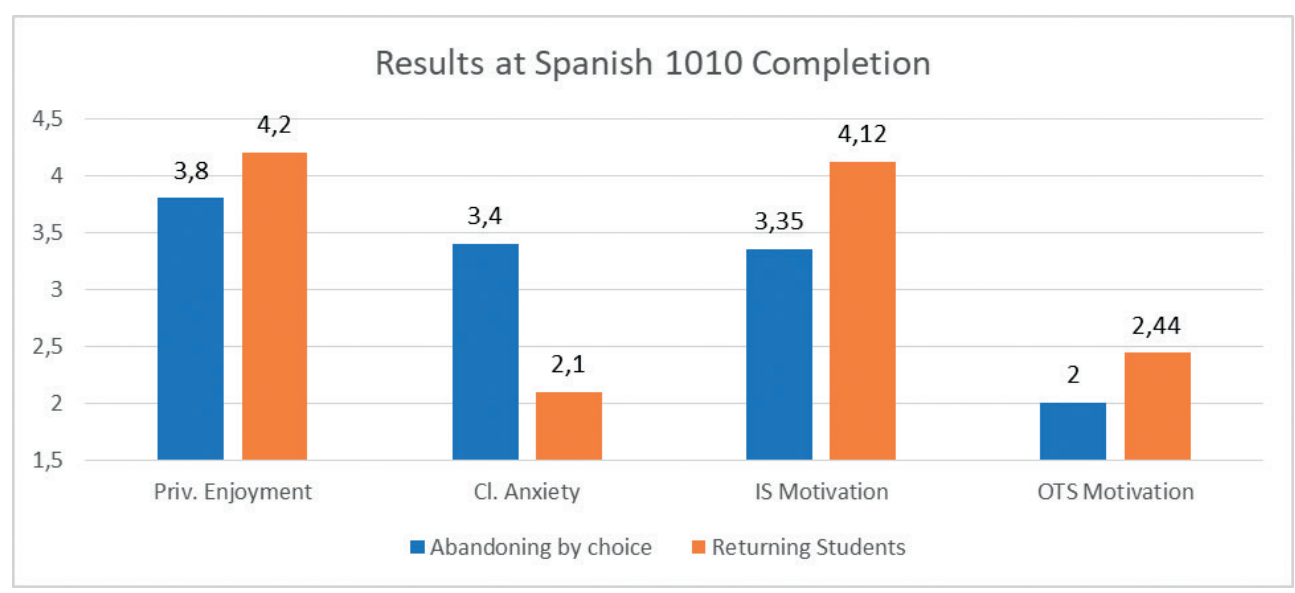

FigURE 5

Most significant divergence in results obtained from subjects who passed SPAN1010, but chose not to return for 1020, and those who passed and returned.

Another interesting factor is that the differential in ought-to-self motivation due to the influence of faculty is visibly lower for this group. When asked whether "It's important for me to perform well in class so my instructor is not disappointed," this group scored an AV of 3.12 (Med: 3, SD: 1.24), whereas the scores for the entire cohort were significantly higher $(\mathbf{3 . 8 6}, \mathbf{4}, \mathbf{0 . 8 7})$. The large standard deviation is due to the divergence in responses between the seven students in the 14-17 age group and the two students in the 18-25, with much higher scores for the latter. This, combined with the small size of the sample (just nine subjects), takes away from the statistical significance of the results, but they can be accepted with an exploratory value, as an area to research in future empirical studies.

\section{Conclusion}

The experiment results show a statistically significant difference in the linguistic and cultural attitudes expressed by students who enroll in Spanish and the general student population, with the latter holding more negative views both towards the language and its speakers. There is also an observable difference between students who complete the course and those who drop out early, who also hold more negative views than the complete cohort. These results confirm those obtained by Acheson et al. (2015) for younger students in the same cultural and sociological region. Considering the results achieved by Acheson et al. (2015) to improve these perceptions in their students through global and cultural awareness instruction, it is safe to recommend a similar approach for Chattanooga State Community College, as a way not only to fulfill one of its institutional learning outcomes, but also to increase enrollment, retention, and success in their L2 Spanish program. 
Students who abandon the program-either early, or at the end of the coursereport more ANX than those passing the course successfully and returning the next year. There is also a clear negative correlation between ANX and academic success (-0.333). However, ANX results are complex and difficult to interpret, as they are significantly skewed by gender, and its relationship with ideal-self and ought-to-self motivation is not clear. The relationships between enjoyment and retention and success are easier to establish, particularly between private enjoyment and success, with a correlation of $\mathbf{0 . 3 0 1}$ with academic results and $\mathbf{0 . 4 0 1}$ with ideal-self motivation. The results in this experiment confirm the findings of Dewaele \& Dewaele (2017), Dewaele et al. (2017), and Saito et al. (2018).

Engaging, meaningful instruction can have an impact on attitudes, enrollment, and private enjoyment, according to the experiment results. Instructors have more impact on $\mathrm{SE}$ and, more interestingly, on ought-to-self motivation. In an area like the American Southeast, in which the target language, Spanish, has low social prestige, the presence of a positive authority figure vouching for it can significantly alter the social perception the subjects hold of the language. We can observe this in the results of the third survey, which show that those students who stayed in the program had an important source of ought-to-self motivation in pleasing the instructor. This was less of a factor in the students who chose not to return. This aspect of instructor influence on classroom emotions and motivation should be further explored through case studies.

This study presents several weaknesses, such as the limited size of the sample, which could be corrected either by repeating the study on a larger sample or triangulating it with future similar studies. Unfortunately, despite the increasing number of studies exploring the relationship between motivation factors, classroom emotions, and proficiency development and/or success in the L2 classroom, there is currently a lack of such studies in two-year institutions in the US, which makes that triangulation less relevant. Also, social desirability bias might have impacted the answers provided by the subjects when attempting to measure their attitudes towards both the Spanish language and its speakers.

There are several future opportunities for research emerging from this study. Case study research could help better understand the relationship between L2 motivation, L2 enjoyment, and classroom ANX. The current study should be replicated with a larger sample, to further explore the relationship between linguistic and cultural attitudes and global and cultural awareness in students. A similar study with subjects from a four-year institution in the same area would help explore the differences between these two higher education student populations. Finally, it would be interesting to conduct research focused on the differences by gender when reporting linguistic and cultural attitudes, as well as classroom emotions.

\section{REFERENCES}

Abrajano, MARISA; hajnAl, zoltán L., (2017), White backlash: immigration, race, and American politics. Princeton University Press. 
ACHESON, KRIS; NELSON, MATTHEW; LUnA, KeRA, (2015), "Measuring the impact of instruction in intercultural communication on secondary Spanish learners' attitudes and motivation." Foreign Language Annals, 48(2), 203-217. https://doi.org/10.1111/flan.12132

BOO, ZANN; DÖRNYEI, ZOLTÁN; RYAN, STEPHEN, (2015), "L2 motivation research 2005-2014: Understanding a publication surge and a changing landscape." System, 55, 145157. https://doi.org/10.1016/j.system.2015.10.006

Cochran, Jeff l.; Mccallum, R. Steve; Bell, Sherry Mee, (2010), “Three A's: How do attributions, attitudes, and aptitude contribute to foreign language learning?" Foreign Language Annals, 43, 566-582. https://doi.org/10.1177\%2F1932202X1002200106


VAN MENSEL, LUK, (20I8), "Classroom anxiety and enjoyment in CLIL and non-CLIL: Does the target language matter?" Studies in Second Language Learning and Teaching. 8(1), p. 47-71.

DeWAele, JeAN-MARC; DeWAele, Livia, (2017), "The dynamic interactions in foreign language classroom anxiety and foreign language enjoyment of pupils aged 12 to 18. A pseudo-longitudinal investigation." Journal of the European Second Language Association, 1(1), 12-22. http://doi.org/10.22599/jesla.6

Dewaele, JeAn-MARC; MCintyre, Peter, (20I4), “The two faces of Janus? Anxiety and enjoyment in the foreign language classroom." Studies in Second Language Learning and Teaching, IV-2, 237-274.

Dewaele, jean-marc; whitney, john; saito, kazuya; dewaele, Livia, (2017), "Foreign language enjoyment and anxiety: The effect of teacher and learner variables." Language Teaching. Published online February 17, 2017. https://doi. org/10.1177\%2F1362168817692161

DöRNYEI, ZOLTÁN, (20I4), The psychology of the language learner: Individual differences in second language acquisition. London: Routledge.

DöRNYEI, ZOLTÁN; USHIODA, Ema, (Eds.), (2009), Motivation, language identity and the L2 self. Clevedon, UK: Multilingual Matters. https://doi.org/10.4324/9781410613349

Fishman, JOSHUA, (2004), "Multilingualism and non-English mother tongues." In FINNEGAN, EDWARD; RICKFORD, JOHN R., (Eds.), Language in the USA: Themes for the twenty-first century (pp. 115-132). Cambridge, UK: Cambridge University Press.

GARDNer, RoBert C., (I985), Social psychology and second language learning: The role of attitudes and motivation. London: Edward Arnold.

Gardner, robert c.; Lambert, wallace e., (1972), Attitudes and motivation in secondlanguage learning. Rowley, MA: Newbury House.

Gardner, robert c.; Smythe, Padric C.; Clément, richard, (1978), Attitudes and motivation test battery. London, Canada: University of Western Ontario.

Horwitz, ElAine K., (2017), "On the misreading of Horwitz, Horwitz, and Cope (1986) and the need to balance anxiety research and the experiences of anxious language learners." In gkonou, Christina; DAUbney, MARK; DEWAEle, JEAN-MARC, (Eds.), New insights into language anxiety: Theory, research and educational implications (pp. 31-47). Bristol, UK: Multilingual Matters. 
Horwitz, elaine K.; Horwitz, michael b.; Cope, joann, (1986), "Foreign language classroom anxiety." The Modern Language Journal, 70, 125-132. https://doi. org/10.1111/j.1540-4781.1986.tb05256.x

Juszkiewicz, Jolanta, (2017), “Trends in Community College Enrollment and Completion Data", Washington, DC: American Association of Community Colleges. http:// hdl.handle.net/10919/86967

LeEMAn, JENNIFER, (2015), "Heritage language education and identity in the United States." Annual Review of Applied Linguistics, 35, pp. 100-119. https://doi.org/10.1017/ S0267190514000245

LIPPI-GREEN, ROSINA, (2012), English with an accent: Language, ideology, and discrimination in the United States (2nd ed.). New York: Routledge.

LOONEY, DENNIS; LUSIN, NATALIA, (2018), "Enrollments in Languages Other Than English in United States Insitutions of Higher Education, Summer 2016 and Fall 2016: Preliminary Report". Modern Language Association of America. https://files.eric.ed.gov/ fulltext/ED590075.pdf

MA, Jennifer; BAum, SAndy, (2016), "Trends in Community Colleges: Enrollment, Prices, Student Debt, and Completion”. College Board Research Brief, 4, 1-23. https:// go.valenciacollege.edu/academics/programs/undergraduate-research/documents/trends-incommunity-colleges-research-brief.pdf

Macintyre, Peter, (20I7), "An overview of language anxiety research and trends in its development." In Gkonou, Christina; Daubney, Mark; Dewaele Jean-Marc, (Eds.), New insights into language anxiety: Theory, research and educational implications (pp. 11-30). Bristol, UK: Multilingual Matters. http://www.academia.edu/download/53691816/ MacIntyre_Overview_and_Trends_FINAL.docx

MACintyre, PETER; GARDNER, ROBERT C., (1989), “Anxiety and second-language learning: Toward a theoretical clarification." Language Learning, 39, 251-275. https://doi. org/10.1111/j.1467-1770.1989.tb00423.x

Macintyre, Peter; GRegersen, TAMmy, (2012), "Emotions that facilitate language learning: The positive-broadening power of the imagination." Studies in Second Language Learning and Teaching, 2, 193-213.

PaPi, mostafa; TeImouri, YASSER, (20I4), "Language learner motivational types: A cluster analysis study." Language Learning, 64, 493-525. https://doi.org/10.1111/ lang. 12065

Rivers, William; Robinson, John; HARWood, PAUl; Brecht, Richard, (2013), "Language votes: Attitudes toward foreign language policies." Foreign Language Annals, 46, 329-338. https://doi.org/10.1111/flan.12048

Saito, Kazuya, dewaele, Jean-Marc, ABE, Mariko \& in’nami, Yo, (2018), "Motivation, Emotion, Learning Experience, and Second Language Comprehensibility Development in Classroom Settings: A Cross-Sectional and Longitudinal Study." Language Learning, 68(3), 709-743. https://doi.org/10.1111/lang.12297

Wesely, Pamela, (2010), "Student Attrition from Traditional and Immersion Foreign Language Programs." Language and Linguistics Compass, 4/9, 804-817. https://doi. org/10.1111/j.1749-818X.2010.00241.X 